\title{
Global climate change education: technology transfer to schools
}

\author{
Sandra Henderson, Steven R. Holman \\ ManTech Environmental Technology, Inc., U.S. EPA Environmental Research Laboratory, Corvallis, \\ 200 SW 35 th St., Corvallis, Oregon 97333 , USA
}

\begin{abstract}
As part of the overall reform currently underway in pre-college science education, efforts are being made to link science education with 'real world' environmental issues. Global climate change is an ideal environmental topic to capture student attention. In addition, scientists are being encouraged to establish linkages with science teachers through partnerships and collaborations that focus on teacher enhancement and curriculum development. Scientists at the U.S. Environmental Protection Agency Environmental Research Laboratory in Corvallis, Oregon, have established a partnership with science teachers for the purpose of designing an integrated science curriculum (pre-college level) addressing global climate change. The scientific foundation of the curriculum is based on (1) the fundamental components of the climate system, (2) the scientific uncertainties involved in predicting the rate and magnitude of climate change and (3) the likely impacts of rapid climate change of ecosystems. The curriculum will be available for distribution in summer 1993
\end{abstract}

\section{INTRODUCTION}

It would be difficult to live in our information-rich society and not be familiar with phrases such as 'global warming', 'the greenhouse effect', and 'global climate change'. But, how many people actually understand what these terms mean? Most of the general public does not have adequate scientific knowledge to understand the scientific basis of global climate change, its' causes, or possible effects. Recent reports note the alarming state of scientific illiteracy in this country (AAAS 1989. American Chemical Society 1989, Massey 1989), and an array of solutions have been proposed to alleviate the problem. One suggested solution involves collaboration between scientists and the pre-college educational community (AAAS 1989, Atkin \& Atkin 1989).

The pre-college school system is ideal for transferring scientific information on global climate change issues. In science education, there is a move away from science being taught as a collection of facts to be memorized and towards the current emphasis on topics that encourage critical thinking and experimentation and on topics that are timely and relevant to student lives, e.g. global climate change (Collette
\& Chiappetta 1989, DeBoer 1991, Cheek 1992).

A recent report by the Federal Coordinating Council on Science, Education, and Technology (FCCSET 1991) determined that the top priorities in science education reform should be teacher enhancement and curriculum development at the pre-college level. Scientists can help with teacher enhancement and curriculum development through partnership efforts where scientists contribute relevant, up-to-date technical information and resources, familiarize teachers with the nature of science, and help teachers become more comfortable with the uncertainty inherent in science. In addition, scientists can serve as important role models. We do not suggest that classroom teachers are not doing their job and that with input from scientists, science education will miraculously turn around. Most classroom teachers are dedicated professionals, often with tremendous workloads, few resources, overcrowded classes, and constrained by a host of social and political considerations. Teachers lack the time to 'keep up' with the current state of science and to incorporate that information into the curriculum. We are suggesting that scientists have the ability and the resources to assist in filling this need. 


\section{SCIENTIST / EDUCATOR PARTNERSHIP}

Considering the priorities described above, scientists at the U.S. EPA Environmental Research Laboratory in Corvallis have participated in a partnership linking scientists and educators for the purpose of designing an integrated science curriculum addressing global climate change for grades 8 through 10 . The partnership involved a significant time contribution from all involved.

In January 1991, 5 global climate change scientists met with 5 middle and high school teachers and a university curriculum development specialist to design the basic framework for a curriculum addressing global climate change (Henderson \& Holman 1992). The scientists brought to the partnership their knowledge and understanding of the complexity of climate change issues as well as their ideas for student activities and experiments. The teachers contributed their expertise in science teaching, understanding student needs, and 'what really works in a classroom'.

The partnership was further encouraged at an intensive, week long writing workshop in June 1991 where a draft curriculum was developed. Throughout the summer, all involved in the project continued editing and informal testing to ready the curriculum for the actual classroom field test in the fall. During the classroom testing phase, the teachers kept detailed notes indicating the strengths and weaknesses of the various activities and made adjustments where appropriate. The scientists met with the partner teachers and their classes throughout the 1991-92 academic year and were available as resources.

Based on teacher comments and experiences, a final draft of the curriculum was completed during the summer of 1992. The revised copy was sent to global climate change scientists and university science educators for review. The finalized curriculum will be distributed through the ERIC Clearinghouse for Science, Mathematics, and Environmental Education. It will be available late summer or early fall of 1993.

The scientific foundation of the curriculum is based on: (1) the fundamental components of the climate system, including the hydrosphere, atmosphere, and biosphere, (2) the scientific uncertainties involved in predicting the rate and magnitude of climate change, and (3) the likely impacts of rapid climate change on ecosystems. The National Science Teacher's Association, in a 1982 position statement (NSTA 1982), stated that the goal of science education was to 'develop scientifically literate individuals who understand how science, technology, and society influence one another and who are able to use this knowledge in their everyday decision-making'. It was the intent of the global climate change curriculum project to contribute to this goal.

\section{GLOBAL CLIMATE CHANGE CURRICULUM UNITS}

The curriculum is comprised of 5 units with 15 activities (Table 1). The activities are designed to be integrated into the existing science curriculum from grades 8 to 10. Each activity is written with the developmental needs of the students in mind, recognizing that adaptations will be necessary depending on the unique characteristics of each group of students in each part of the country.

This curriculum is intended to be flexible, with allowance for the teacher to select some or all of the activities. Units build on the content and learning of previous units, yet are not dependent on previous activities. Thus the units and activities may be implemented sequentially or be ordered to fit existing curriculum organization of content. The activities are designed to be 'teacher friendly' by including background information and a step-by-step description of the experiments. Student guides are also included. The materials needed for the activities are readily available and inexpensive.

Effort was made to incorporate 'hands-on' experiential learning in each activity. Student exercises include data generation, recording, and analysis as well as problem solving, speculation and decision-making Students will be immersed in the process of being scientists while considering actual problems facing the scientific community and general public today.

Climate unit. The activities in this unit address the differences between climate and weather, the factors that influence climate, the relationship between biomes and climate, the changes in Earth's climate over time, and reviews the work of paleobotanists in their study of ancient climates.

In this last activity, students analyze pollen found in sample 'sediment' to explore the way that scientists gather information about plant species that grew in the past, and how they use that information to determine past climates.

Greenhouse eifect unit. The activities in this unit are designed to familiarize students with the properties of a greenhouse, examine the factors that influence greenhouses, and, determine what makes the earth's atmosphere like a greenhouse. Students make model greenhouses from plastic, 2 l soda bottles. The 'greenhouses' are equipped with plastic thermometers and placed under a $150 \mathrm{~W}$ bulb. In the first experiment, students observe the effect of visible light absorption and conversion to infra-red radiation and the resulting increase in greenhouse temperature. In the second activity, students set up a selection of model greenhouses with different properties (e.g color of surfaces inside the greenhouse, type of surface, transparency of 
Table 1 Units and activities from the global climate change curriculum

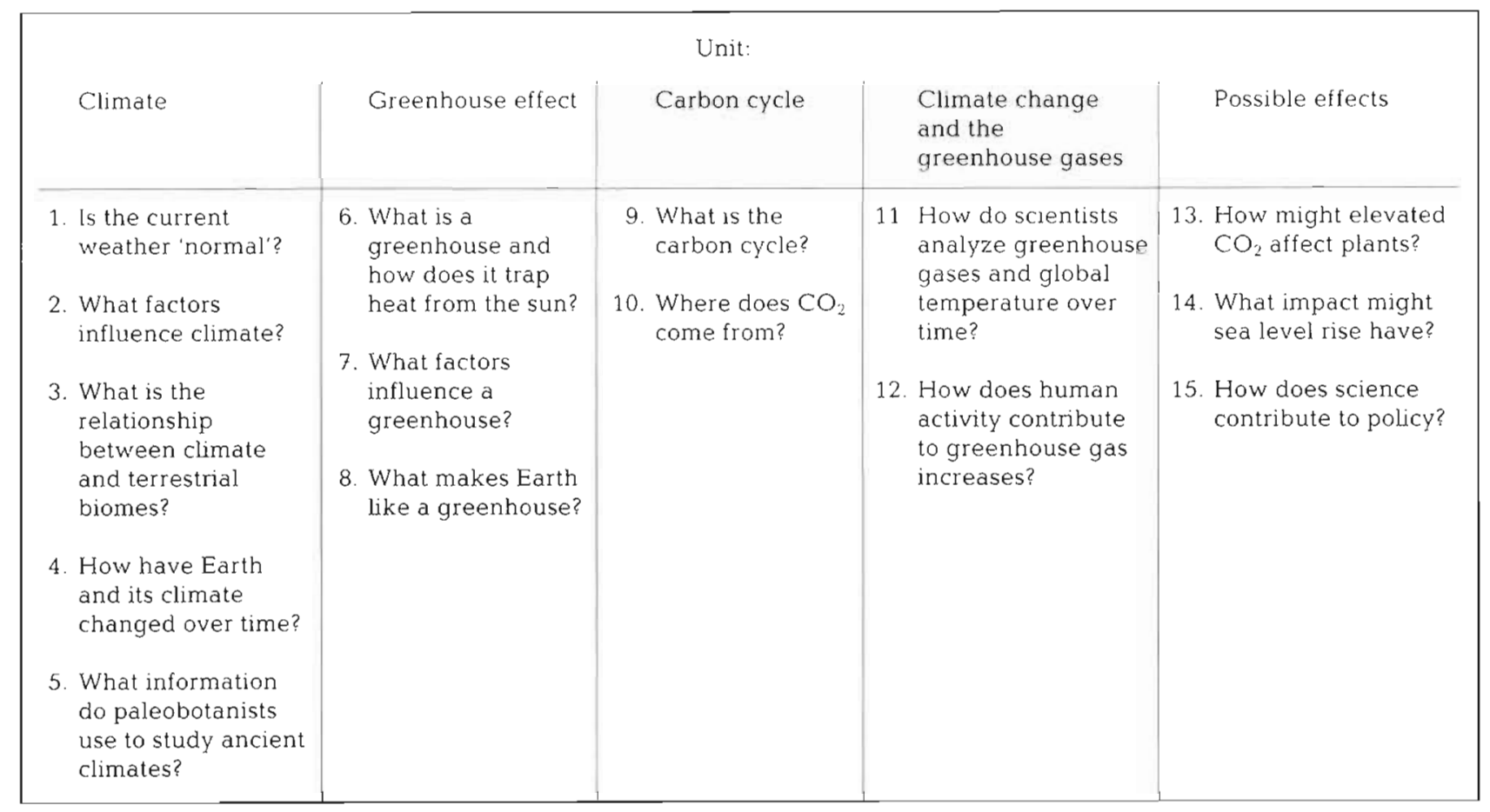

greenhouse cover) and observe, record, and graph the differences in temperature between them.

Carbon cycle. Activities in this unit address the carbon cycle, sources and sinks of $\mathrm{CO}_{2}$, and lead the students to consider the connection between the carbon cycle and the role of carbon in the greenhouse effect. The students conduct a series of experiments using a chemical indicator to: (1) detect the presence of $\mathrm{CO}_{2}$ (2) determine if animals are a source of $\mathrm{CO}_{2}$, (4) determine if plants are a source of $\mathrm{CO}_{2}$, and (4) test for the presence of $\mathrm{CO}_{2}$ in fossil fuels (automobile exhaust).

Climate change and the greenhouse gases. This unit includes activities designed to familiarize students with 'raw' data - its collection, organization, and analysis of greenhouse gas buildup, and the human contribution to greenhouse gas build-up. The students learn about changes that have occurred in some greenhouse effect levels and average temperatures within the recent past. In addition, this unit includes short biographies about the people behind the science. The purpose of the biographies is to acquaint the students with scientists as people.

Possible effects unit. This unit focuses on the less certain aspects of global climate change. What might happen and what do scientists base these prediction on? The students undertake an experiment to determine how plants would respond to increases in $\mathrm{CO}_{2}$ using control and treatment groups. Other activities examine the tools scientists use to predict global cli- mate change, consider the poteritial impact of sea level rise, and determine the way that scientific knowledge contributes to policy decisions regarding global climate change.

\section{CONCLUSION}

The creation of the global climate change curriculum has required dedicated teamwork from the scientists and educators involved. As the final curriculum is disseminated to schools, teachers will be encouraged to seek partnerships with scientists in their locality for the purpose of sharing scientific knowledge and extending curriculum activities. Scientists and educators working together can make a difference in the quality of science education in our schools.

Acknowledgements. We thank Bill Ferrell, Gray Henderson, Karen Hollweg, Lauri Shainsky, and Mike Spranger for their review. The research described in this article was funded by the U.S. Environmental Protection Agency. This document was prepared at the EPA Environmental Research Laboratory in Corvallis, Oregon, through contract \#68-C8-0006 to ManTech Environmental Technologies, Inc. It has been subjected to the Agency's peer and administrative review and approved for publication. Mention of trade names or commercial products does not constitute endorsement or recommendation for use. 


\section{LITERATURE CITED}

AAAS (American Association for the Advancement of Science) (1989). Science for all Americans. AAAS, Washington, DC

Atkin, J. M., Atkin, A. (1989). Improving science through local alliances. Network Publications, Santa Cruz, CA

American Chemical Society (1989). Statement of the American Chemical Society: education policies for national survival. ACS, Washington, DC

Cheek, D.W. (1992). Thinking constructively about science, technology, and society education. State University of New York Press, Albany

Collete, A. T., Chiappetta, E. L. (1989). Science education in the middle and secondary schools. Merrill Publishing Co., Columbus, $\mathrm{OH}$
DeBoer, G. E. (1991). A history of ideas in science education. Teachers College Press, New York

FCCSET (Federal Coordinating Council on Science, Education and Technology) Committee on Education and Human Resources (1991). By the year 2000: first in the world. Washington, DC

Henderson, S., Holman, S. R. (1991). Northwest education heats up: scientists, educators, and the greenhouse effect. NW environ. J. 7(2):368-369

Massey, W. E. (1989). Scientific education in the United States: what the scientific community can do. Science 245 : 915-921

NSTA (National Science Teachers Association) (1982). Science-technology-society: science education of the 1980s. Washington, DC, p. 1-6 